ON THE

CLASSIFICATION, STRUCTURE AND DEVELOPMENT

OF THE

\title{
ECHINOCOCCUS HOMINIS,
}

SHOWING REASONS FOR REGARDING IT AS A SPECIES OF CYSTICERCUS.

Bx ERASMUS WILSON, F.R.S.,

CONSULTINo BURGEON TO THE ST. PANCRAS INPIRMARY; LECTURER ON ANATOMY AND PHYSIOLOGT IN THE MIDDLESEX HOAPITAL.

Received November 4th-Read November 12th, 1844.

Observations on the echinococcus hominis have been heretofore so rare, that I deem myself fortunate in having the opportunity of communicating to the Society some original researches relative to the habits, structure, and development of this curious entozoon.

My observations, hitherto, have been limited to two cases of hydatids, instances of the common acephalo-cyst of the liver, in both of which I discovered the animalcule in question. I was led by this circumstance to infer that the echinococcus must be more common in its occurrence than had previously been imagined, and I find my opinion corroborated by that of Mr. Curling. In a note recently received from this gentleman, he says, "As the echinococcus has been discovered in nearly all the cases of acephalocyst which have come under my observation during 
the last two or three years, I am inclined to think that this, instead of being, as I once supposed, a rare form of hydatid, is the most common one infesting man."

Dr. Livois, the author of a work, lately published in Paris, entitled, "Recherches sur les Echinococques,"-(a work which I regret that I have been unable to obtain, but of which a notice appeared in the British and Foreign Medical Review for January 1844 ,) - considers them to exist in every case of acephalo-cyst.

From these statements it is obvious that the echinococcus is a common parasite of the human frame, and that it is probably present in the majority of instances in which acephalo-cysts occur. On this account, therefore, independently of the scientific interest connected with the knowledge of a curious animal, I have concluded that a description of the habits, structure and development of this parasite would be deemed acceptable by the Society; and to this subject $I$ at once address myself.

The term echinococcus (exivos, echinus, коккоs, granum) was applied by Rudolphi to the acephalocyst and its contained animaicules in conjunction, and in this sense the term has been used by Mr. Owen in his article "Entozoa" in the Cyclopedia of Anatomy and Physiology, and by Mr. Curling in the Society's Transactions. Müller* employs the term in its more significant meaning, as referrible to the animalcules

* Archiv fur Physiologie, \&c. 1836. Jahresbericht im Jahre 1835, page 107. 
alone, and $\mathrm{Mr}$. Owen in a later work* adopts the same application of the term. The question is not unimportant, for the former use of the term assumes a speciality in the acephalo-cyst, while the latter recognises the animalcules as independent beings or as parasites of the common acephalo-cyst. My own observations lead me to the latter conclusion, and they further go to prove that the echinococcus has no claim to consideration as a distinct genus, but is in reality a species of the genus cysticercus, to which species, for reasons hereafter to be detailed, I think the term " cysticercus pedunculatus" peculiarly applicable.

The acephalo-cyst in which the echinococcus is found, is identical with that in which the animalcules are absent. Nothing is more true than the fact stated by Müller and admitted by Dr. Livois, that in some acephalo-cysts the animalcules are present, while in others, from the same subject, they are absent, and there may be cases in which they are wanting in all the cysts, although such cases are probably rare. The acephalo-cyst is composed, as is well known, of two tunics-an outer tunic, which is semi-transparent, laminated, finely granular in minute texture and highly elastic; and an internal layer, (fig. 1, ) consisting of a thin and very delicate membrane studded with innumerable transparent cells, varying in extremes of measurement from

* Lectures on the Comparative Anatomy and Physiology of the Invertebrate Animals, 1843. 
$\frac{1}{10000}$ to $\frac{1}{300}$ of an inch in diameter; but having a medium size of $\frac{1}{2000}$ of an inch.

This membrane is the seat of development of the echinococcus, and to this, in a fresh acephalo-cyst, they are found connected by means of a very delicate proper membrane, either singly or more commonly in clusters, varying in numbers of individuals from two to one hundred (fig. 3). Some idea of the numbers of echinococci inhabiting a single acephalocyst of moderate size, may be inferred from the fact, that in one cyst of the size of a small hazel-nut I counted forty clusters; in several of the clusters there were eighty individuals, and in the entire cyst not less than one thousand. Now, when it is recollected that the majority of acephalo-cysts in an ordinary hydatid tumour would be larger than the one here described, and that of these there may be from one hundred to one thousand present, the entire number of living beings nourished at the expense of the fluids of the diseased person, in such a case, must be enormous.

Acephalo-cysts are generally very closely packed in an hydatid tumour, so that they cannot be re. moved without some degree of pressure; from their roundness of form and distension they are not easily brought under examination; and when punctured, their fluid contents issue from the sac in a jet of considerable force, impelled by the contractile power of their elastic tunic. Moreover, if the incision be of a certain size, the sac will roll up and turn itself inside out. These are all reasons why the little 
clusters connected to the internal membrane of the acephalo-cyst should be found detached in the fluid of the cyst, and broken up into their individual components ; a state which I conceive to be the result of violence, but which has been regarded by all authors who have written upon them, as their natural condition when their development is completed. Müller, in referring to the adhesion of the clusters to the internal surface of the acephalo-cyst, remarks, that he conceives this contact to have relation to development.

The echinococcus presents itself to the observer in two states-a contracted and an elongated state. In the former of these, (figs. 4-8,) which, according to my observations, (limited to the dead animal,) is the most common, the echinococcus is more or less globular or oval in form, and slightly flattened at opposite poles. In the latter, namely, the elongated condition, (figs. 9-11,) it offers considerable variety of shape, being usually larger at the cephalic than at the caudal end, displaying generally an apparatus of suctorial prominences and hooklets at the cephalic extremity, being more or less constricted in the middle, and frequently pointed at the caudal end. The ordinary dimensions of the animal in its contracted state are $\frac{1}{200}$ of an inch in the long, and $\frac{1}{230}$ of an inch in the short, diameter; while the largest specimen which $I$ have yet seen in the elongated state measured $\frac{1}{125}$ of an inch in the long, and $\frac{1}{190}$ in the broadest part of its short diameter. 
In structure, the animal is a mere integument, the one half, representing analogically the head and neck, being susceptible of retraction into the other half, which represents the body or caudal portion ; the proper contents of the tegumentary sac being a small number of nucleated granules, and an apparatus (of the existence of which I am not certain) for the retraction of the head and neck. The head is a flat membranous disk which forms the extremity of the neck, and has imbedded in its substance an apparatus of small hooks disposed in a circle. Immediately behind the head are four rounded prominences, of considerable size, placed at equal distances from each other, and consisting each of a prominent rim surrounding a depressed cup; these are suctorial processes. Beyond the suctorial apparatus follows the body or caudal portion of the animal, and at the extremity of the latter is a short process, the peduncle, (figs. 4,7 ,) by which the animal is attached to its own proper membrane or to the internal membrane of the acephalo-cyst.

The integument of the animal is white, thick and opaque (during life, according to Dr. Livois, it is perfectly transparent); it is also pliant, contractile, moderately tough, and composed of nucleated granules. It is thicker in the neck than in the body, and the suctorial prominences are transparent and structureless. When the animal in its contracted state is viewed under the microscope by transmitted light, a dark line may be seen occupying the centre of its longitudinal axis and extending for a variable 
distance from one pole towards the other; this line is the tubular canal of the inverted neck. At the extremity of this line is another, which is transverse in its direction and curved; this latter line indicates the position of the circle of hooklets, and presents some variety in accordance with its direction. The appearances which I am now describing are more distinct in some specimens than in others, they are also better seen when the animal is subjected to moderate compression or to the action of diluted acetic acid. When rendered transparent by the latter means, the entire neck, with its suctorial prominences, may often be distinguished within the body. In this view of the animal aiso, when the head is only partially retracted, I have sometimes seen running from the base of the head to the posterior pole of the body, some delicate lines which appeared to me to be the boundaries of a retractor muscle of the head. This impression is strengthened by observing that in complete contraction of the echinococcus, the posterior pole of the body is drawn in and rendered concave; the entire animal having then the shape of an orange.

When the animal in the contracted state is viewed in its horizontal axis, (fig. 6,) the circle of hooklets appears as a ring in the centre of the body ; an outer and inner circumferential line denote the thickness of the integument, and not unfrequently the suctorial prominences may be distinguished as transparent spaces. In this position, if the animal be transparent, the circle of hooklets may be 
brought into focus in such a manner as to give the appearance of being on the surface of the body.

The elongated state of the animal may be ascertained, if not by its length, at least by its irregularity of form. Viewed in its longitudinal axis, the coronet of hooklets, and two or three suctorial prominences, may be perceived, while in its horizontal or oblique axis, more or less of the four suctorial prominences may be distinguished, with the coronet of hooklets in their midst.

The hooklets are thirty-four in number, seventeen long, measuring $\frac{1}{1050}$ of an inch, and seventeen somewhat shorter (fig. 17). Each hooklet, (figs. 18, 19,20 ,) possesses a gentle curve, is pointed at one end and blunt at the other, and presents a convex and a concave border, and a base which encroaches on the concave border for nearly half its length : the base is moreover distinguished in this aspect by a breadth greater than the rest of the hook, and by a bifid process at its central extremity. This bifid prominence in the base of the hooklet is a considerable and distinct process in the larger forms of cysticercus, in which also the base has the character of an elongated shaft, and the hook is more strongly curved.

I have said that the neck of the animal is terminated by a membranous disk, which is susceptible of assuming the three states of convexity, concavity, or simple flatness. In this membrane the hooklets are imbedded, a small portion only of the point of each projecting free beyond the integument. When the 
disk is viewed in its flat state, the hooklets are seen to be placed on the same plane, their blunt extremities being directed towards the centre of the disk, and their shafts radiating towards its circumference (fig. 17). In this position of the disk, the base of the hooklet is directed towards the body of the animal, and the bifid process at its central extremity is deeply and firmly inserted into the substance of the neck, the point of attachment of this part constituting a kind of pivot upon which the hooklet moves. The movements of the hooklet are such as serve to place it in an erect or depressed position; in the former, the blunt end is drawn backwards, while in the latter it is pushed forwards, in both cases the bifid process being the fixed point upon which the motion is accomplished. The more common position of the hooklets is that in which they are depressed or recurved; in this position the blunt ends are directed forwards, while the sharp ends look backwards, and the convex border outwards (figs. 9, 11). The erect position of the hooklets is less frequent; in this the direction of the ends is reversed, and the concavity of the hook with its base, and the bifid process of the latter, look outwards (fig. 10).

I now come to that character of the echinococcus which I consider worthy of becoming a specific distinction, namely, the peduncle, by which the animal is fixed, either to its own proper membrane, or to the internal membrane of the acephalo-cyst. The peduncle is cylindrical, short and granular. When 
the animal is separated from its attachment, the peduncle offers a variety of appearances, depending on the manner in which it may be torn, and when it is broken close off, an opening is left, which communicates with the internal cavity of the body of the animal. Through this opening I have frequently seen nucleated cells expelled by compression (fig. $8 \mathrm{~g})$. The peduncle has been noticed by Müller, but is regarded by him as a stage in the development of the animal needing further elucidation.

In the course of pursuing the observations on which the preceding account of the echinococcus is founded, I frequently met with animals that had been dead apparently for some time. Some of these retained their elongated form (fig. 11), and were more or less wrinkled and shrivelled; others were contracted, but had lost their characteristic orange or pumpkin-shaped form, and exhibited a number of transparent cells, apparently adipose cells of various magnitude, scattered irregularly through their substance (figs. 12, 13); others again were reduced to a mere mass of cells (figs. 14, 15), and could only be identified by the remains of the circle of hooklets being apparent in some; while others, still further advanced in degradation and much smaller, had the appearance of the corolla of a flower with a single circle of petals (fig. 16). Occasionally I met with instances in which an entire cluster still contained in their proper membrane had undergone these changes, but not all of them in the same degree, so that I was enabled to observe all the grada- 
tions here described, within the circuit of the same membrane. Indeed, without such a confirmation as this observation afforded me, I should have been unable to speak positively to the identity of bo dis so very unlike their original form.

Development.-In my description of the internal membrane of the acephalo-cyst, I have stated that this membrane is studded with innumerable transparent cells, but amongst these cells I have observed here and there one which was more opaque than the rest. All the cells, both transparent and opaque, contain smaller cells, but, in the latter, the contained cells are more defined and generally nucleated. Such a cell as that which $I$ am now describing, measured $\frac{1}{2000}$ of an inch in diameter (figs. 21, 22); another measured $\frac{1}{900}$ of an inch (fig. 24); while between these there was every transition of size. These compound nucleated cells I conclude to be the earliest stage in the development of the echinococcus.

The second stage of development appears to result from the rupture of the membrane of the preceding cell, and the diffusion of the contained nucleated cells in the form of a small opaque patch in the substance of the internal membrane of the acephalo-cyst. Two patches of this kind measured, the one $\frac{1}{600}$ (fig. 25), the other $\frac{1}{480}$ of an inch in breadth, and were composed of nucleated cells measuring $\frac{1}{3000}$ of an inch.

The next change which occurs is the protrusion of the superficial stratum of the lining membrane of the acephalo-cyst by multiplication of the cells of 
the central part of the patch. In this stage the little mass of cells forms a globular prominence on the surface of the membrane, and one cell of large dimensions may be distinguished by its transparency in the centre of the rest ; the membrane which invests the little mass is the enclosing membrane of the future animal. A small globular mass, such as I am now describing, measured $\frac{1}{500}$ of an inch in diameter (fig. 26). Another of greater length, which assumed a pyriform shape, measured $\frac{1}{275}$ of an inch in its long diameter (fig. 27) ; another, more decidedly pyriform, $\frac{1}{250}$ of an inch; and a third $\frac{1}{175}$.

While this process is going on, as respects the first developed animal, the patch from which it originated is increasing in size, and other protrusions are taking place around its base, which go through the same phases and produce other individuals (fig. 28). From this circumstance, animals in various stages of development may be seen in the same cluster, and enclosed in the same proper membrane.

With elongation of the embryo, the large central cell also enlarges, and the cells in the central axis of the embryo all assume a larger size than the rest. Subsequently these larger cells appear to coalesce, and then a tubular canal occupies the central axis of the embryo, commencing by an enlarged expansion in the bulbous extremity of the animal, and terminating by a similar expansion at its point of connection with the opaque patch (fig. 29). At the distal end of the tubular canal a dark transverse body, appears by degrees : this is the future circle of hook- 
lets ; and from it, some lines, indicating the situation of the neck, may be traced to the extremity of the animal, and the aperture for the eversion of the neck begins to be formed (fig. 30 ).

I regard as not the least interesting in relation to the development of this animal, the question,What becomes of the tubular canal which is primitively formed in the interior of the embryo? I believe the answer to this question to be, that this tubular canal remains as a natural part of the organization of the perfect animal ; that in the latter it is modified so as to perform the office of a retractor muscle; and that a portion of this same tubular cord, extending beyond the periphery of the animal, maintains the permanent character of peduncle. This view of the nature of the peduncle will explain the formation of the aperture in the posterior pole of the animal when the peduncle is torn off, and the consequent escape of granules through the opening when the body is compressed.

It may be expected that I should say something in explanation of the functions of the organs possessed by the animal; but concerning these I can offer no satisfactory hypothesis. The creature has no mouth, and is therefore nourished by imbibition; it is pedunculate, and has no organs of progression. But what purpose can the hooklets fulfil? I can only reply to this question by asking,-What purpose do they fulfil in the cell-bound cysticercus cellulosus, or in the gigantic cysticerci of quadrupeds? What can be the use of suctorial organs to a pedunculate vol. XxviII. 
animal ? The only solution of which these questions admit, is, that the type of organization which nature bestows on a particular group of animals is uniform, however different the circumstances of individual animals may be ;-that the mammary glands, for example, are a type of a large class of animals, but perform an office only in a particular sex.

On the identity of the echinococcus with the cysticercus, it is unnecessary to dwell. The characters of the genus are, a head provided with hooklets, a neck supporting four suctorial processes, and susceptible of retraction within the body, and a membranous cyst-like body. All these characters are present in the echinococcus : the situation, the number, the general form of the hooklets, and their arrangement, are the same in both, and the suctorial processes are the same. The neck, it is true, is shorter in echinococcus than in cysticercus, and the cyst-like body thicker and less expanded ; but these are merely comparative differences. The peduncle however is an important distinction, and merits, I think, the notice bestowed on it in this paper. In describing the structure of the animal, I referred to the probable existence of a retractor muscle. Nothing like a retractor muscle has, as far as I know, been described in the cysticercus; but in a cysticercus which $I$ examined recently, I found such a muscle, and have prepared it for preservation. 
Figures illustrating the structure and development of the Echinococcus hominis.*

Fig. 1.-A portion of the internal membrane of an acephalo-cyst, magnified 155 times. The irregularities on its surface are cells varying in diameter from $\frac{1}{10000}$ to $\frac{1}{300}$ of an inch, the common size being $\frac{1}{2000}$.

Fig. 2.-A group of cells remarkable for their circular form, and for the large size of the included secondary cells. They measured $\frac{1}{1250}$ of an inch in diameter, and were associated with numerous small globular cells, measuring $\frac{1}{6000}$ of an inch. The figure is magnified 310 times.

Fig. 3.-Groups of echinococci, contained within a delicately thin proper membrane; by which they are connected with the internal membrane of the acephalo-cyst. Magnified 38 times.

Fig. 4.-A small portion of the proper membrane of the echinococci, showing the pedunculate connection between these animals and the membrane The point of attachment is the posterior pole of th animal.

Fig. 5.-An echinococcus, as seen in its longitudinal axis, the head retracted; magnified 155 times. $a$. The infundibiliform aperture of the tubular canal, formed by the retraction of the head. $h$. The circle of hooklets and head. $r$. The retractor apparatus of the head. $o$. The caudal aperture caused by the 
rupture of the peduncle. s. $s$. Two of the suctorial processes seen through the semi-transparent integument of the animal. $t$. The granular tegument.

Fig. 6.- An echinococcus viewed transversely; the head being directed towards the observer. In this figure the membranous disk, which the hooklets encircle, is seen. s. s. Suctorial processes. Magnified 155 times.

Fig. 7.-An outline figure, showing the animal with the head partly retracted. $p$. A portion of the peduncle.

Fig. 8.-The animal more retracted, having three of the suctorial processes apparent through the transparent parietes. $g$. Some of the granular contents of the animal, expelled through the aperture left by the torn peduncle, and still remaining connected with it.

Fig. 9.-An animal showing the head entirely extended; the four suctorial processes seen. $d$. The membranous disk encircled by the hooklets, rendered convex by the contraction of the neck.

Fig. 10.-An animal in a similar state, exhibiting an erect condition of the hooklets.

Fig. 11.-Two specimens of the echinococcus, shrivelled and deformed.

Figs. 12-16, Exhibit states of degradation of the animal, occurring after death. The form of the creature is lost; large transparent cells (adipose cells?) are seen in its interior, and finally it is reduced to a small cluster of nucleated particles, re- 
cognisable only as the remains of the animal by the presence of the circle of hooklets ; as in fig. 14.

All the figures from fig. 5 to fig. 16 are magnified 155 times.

Fig. 17. - The circle of hooklets seen upon its under surface, and magnified 456 times. The hooklets are thirty-four in number; seventeen long, and seventeen short.

Fig. 18.-Lateral views of the separate hooklets. $b$. The base. c. The central extremity, or bifid process of the base.

Fig. 19.-Hooklets viewed upon the concave or inferior border. $c$. The bifid process of the central extremity of the base.

Fig. 20.-A diagram, illustrating the movements and position of the hooklets. The dotted line represents the outer surface of the neck, and runs through the fixed point of the three hooks. $f$. A hooklet in the erect position, as in fig. 10. g. A hooklet in the horizontal position, as in fig. 17. $k$. A hooklet in the depressed or recurved position.

Figs. 21-30, Illustrate the development of the echinococcus; figures $21-24$ are magnified 210 times; and figures 25-30, 155 times.

Figs. 21-25.-Masses of nucleated granules; in the interior of figure 23 a large nucleated cell is seen.

Figs. 26, 27.-The nucleated masses assuming a pyriform shape. They are connected by a disk of smaller granules to the membrane, from which they 
grow, and exhibit a transparent cellular space in the centre.

Fig. 28.-A cluster of several pyriform masses of granules ; in each the transparent centre is perceptible.

Figs. 29, 30, Exhibit a more advanced stage of development ; in which the head is formed, and the canal for the extension of the head is seen.

Fig. 31.-A sketch of four echinococci ; two perfectly formed, and two in progress of development, connected by peduncles with the same granular spot. 
Vol.XXIII. PL.

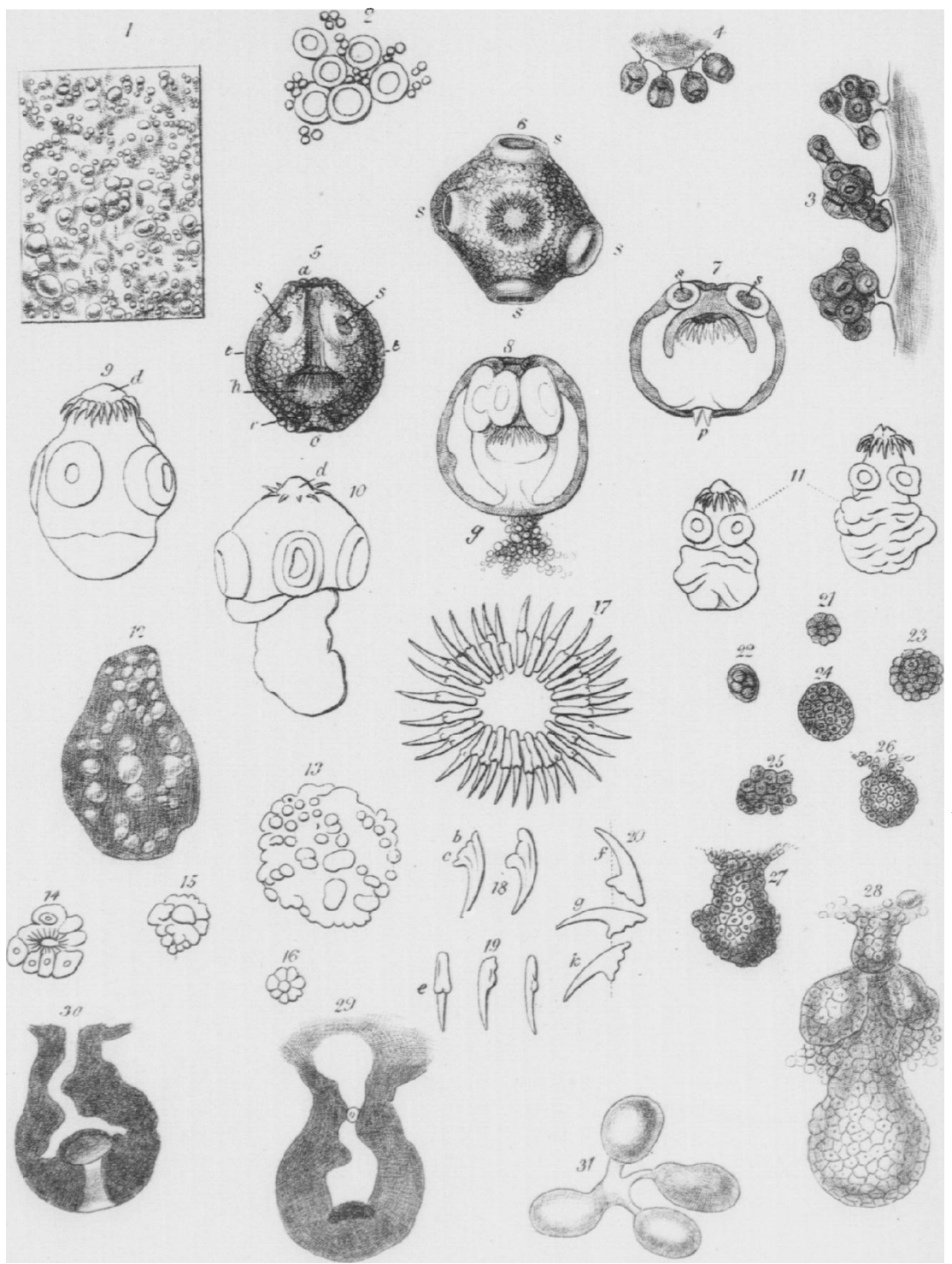

